\title{
It's time to put maternal suicide under the microscope
}

\author{
Kirsten Patrick MB BCh
}

See also the research article by Vigod and colleagues on page 1129 and at www.cmaj.ca/lookup/doi/10.1503/cmaj.122028

$\mathrm{P}$ olice in Manitoba are currently investigating the July deaths of a 32-year-old mother and her 2 children in Winnipeg. ${ }^{1}$ The children, one aged 3 months and the other 2 years, were found unconscious at the family home by emergency personnel responding to a 911 call. The body of the children's mother, Lisa Gibson, was found in the Red River 3 days later. Media reports have suggested that Ms. Gibson had sought help for postpartum depression after the birth of her second child. ${ }^{1}$ This incident serves as a stark reminder that postpartum depression can be a killer, although the official cause of Ms. Gibson's death is yet to be established.

Many women struggle with the stigma of being desperately sad after what is popularly portrayed as the happiest of life events. It can be difficult to understand, let alone empathize with, how a mother could become so depressed as to commit suicide or, worse, infanticide. We may believe that maternal death due to psychiatric illness is vanishingly rare and therefore not a high priority. Yet consider the findings of The Sixth Report of the Confidential Enquiries into Maternal Deaths in the United Kingdom. In auditing maternal deaths in the UK in 2000 through 2002, the report found that psychiatric illness was the largest cause of maternal deaths overall during that period more women who had delivered a baby in the previous 6 months died from suicide than from any other pre-existing medical illness that might complicate pregnancy, including heart disease. ${ }^{2}$ This finding served as something of a wake-up call in a developed country where maternal death due to the usual causes (e.g., sepsis and hemorrhage) had declined substantially by the end of the 20th century.

The UK, along with several other countries, analyzes maternal deaths on a case-by-case basis to identify contributing factors. Canada, however, does not. The purpose of such audits is to find out exactly why women die after having a baby to try to prevent it. So, what does Canada do to find out why new mothers die? The Public Health Agency of Canada undertakes maternal mortality surveillance by analyzing routinely collected data from all provinces except Quebec. However, teasing out deaths from psychiatric causes is tricky, and there is great potential for underreporting suicide owing to varying definitions and categorization of death in these data. ${ }^{3}$ Moreover, there is no formal examination of maternal deaths on a case-by-case basis in Canada, which could elucidate the details of any potential failings in care.

How could we do better? First, we must examine individual cases to inform strategies aimed at preventing such unnecessary and tragic loss of life. The deaths of Ms. Gibson and her children are a tragedy. It is critical that these deaths and other maternal deaths be carefully investigated and reported to see if there were potential failings in care - not to lay blame, but to learn and to consider what might be done differently in future.

Second, physicians must recognize postpartum depression for the debilitating condition it is. Most women do not die from postpartum depression, but its effects have been shown to be severe and far-reaching for both mother and child. There are interventions to prevent and treat the condition, although universal screening for all women after birth is not well supported by current evidence. ${ }^{4}$ However, a case-finding approach involving screening for women with known risk factors is strongly advocated. The risk factors for postpartum depression include a history of psychiatric conditions (particularly previous postpartum depression or depression during the index pregnancy), recent stressful life events, domestic violence, social isolation and lack of a supportive partner.

Connecting women with postpartum depression to the right resources can start with simply asking them directly whether they need help. A validated quick approach is to ask "During the past month, have you often been bothered by feeling down, depressed or hopeless?" and "During the past month, have you often been bothered by having little interest or pleasure in doing things?" If the woman answers "yes" to either of these two questions, asking "Is this something you feel you need or want help with?" improves specificity and the ability to rule in depression among antepartum and postpartum women. ${ }^{5}$

Many barriers can prevent women with postpartum depression from receiving effective treatment. We need to do more to find out what these barriers are. Undertaking a regular indepth audit of maternal deaths due to suicide in Canada to examine why some women slip through the cracks would be a good place to start.

\section{References}

1. Decision on inquest into deaths of Manitoba mother, kids to be made in fall. The Globe and Mail (Toronto [ON]); 2013 July 31. Available: www.theglobeandmail .com/news/national/decision-on-inquest-of-manitoba-mother-kids-deaths-to-be-held -until-fall-medical-examiner/article13525541/ (accessed 2013 Aug. 12).

2. Lewis G, editor. The Confidential Enquiry into Maternal and Child Health (CEMACH) Why mothers die 2000-2002: the sixth report of the confidential enquiries into maternal death in the United Kingdom. London (UK): RCOG Press; 2004.

3. Maternal mortality in Canada. Ottawa (ON): Public Health Agency of Canada; 2011. Available: www.phac-aspc.gc.ca/rhs-ssg/maternal-maternelle/mortality-mortalite /index-eng.php (accessed 2013 Aug. 6).

4. Dennis C-L. Preventing and treating postnatal depression. BMJ 2009;338:a2975.

5. Mann R, Adamson J, Gilbody SM. Diagnostic accuracy of case-finding questions to identify perinatal depression. CMAJ 2012;184:E424-30.

Competing interests: See www.cmaj.ca/site/misc/cmaj_staff.xhtml

Affiliation: Kirsten Patrick is deputy editor, $C M A J$.

Correspondence to: $C M A J$ editor, pubs@cmaj.ca

CMAJ 2013. DOI:10.1503/cmaj.131248 